\title{
THE FEMA TRAILER PARKS: NEGATIVE PERCEPTIONS AND THE SOCIAL STRUCTURE OF AVOIDANCE
}

\author{
Matthew R. Lee \\ Frederick D. Weil \\ Edward S. Shihadeh
}

\author{
Department of Sociology, Louisiana State University, \\ Baton Rouge, Louisiana, USA
}

\begin{abstract}
In recent years, negative media attention has fostered the impression that Federal Emergency Management Agency (FEMA) parks are social wastelands filled with criminal elements and other undesirables. FEMA parks have subsequently come to be viewed by some as a major threat to the safety and quality of life of the local communities in which they are situated. This analysis addresses attitudes toward FEMA trailer parks in Baton Rouge after Hurricane Katrina among Baton Rouge residents. Drawing on the Locally Undesirable Land Use/Not in My Backyard (LULU/NIMBY) literature, the contact hypothesis, and a broad paradigm of social status and social control, we hypothesize that spatial proximity, contact, and social status will influence negative perceptions of the parks, while these same factors along with the negative perceptions will influence avoidance behaviors. The results indicate that living near a FEMA park is associated with less negative perceptions, while actually seeing trailer park residents is associated with more negative perceptions and a greater odds of avoidance, particularly changing driving routes. Whites are particularly concerned about crime associated with the parks, but interracial trust reduces negative perceptions of the parks and the likelihood of avoidance. Those who are likely to end up in a FEMA park if they were in the same situation are more friendly toward the parks and less likely to use avoidance techniques,
\end{abstract}

The data used in this article were collected under support from grant number SES-0554572 to the three authors from the National Science Foundation. The findings reported here do not represent the views, opinions, or policies of the National Science Foundation. A draft of this article was presented at the annual meeting of the Mid-South Sociological Association, October 2006 in Lafayette, LA. We appreciate helpful comments from several anonymous reviewers on a prior draft of this article.

Address correspondence to Matthew R. Lee, Department of Sociology, Louisiana State University, Baton Rouge, LA 70803, USA. E-mail: mlee@lsu.edu 
and negative perceptions themselves are strong predictors of avoidance behaviors. We conclude with a discussion of directions for future research.

A major problem confronting disaster relief efforts involves finding accommodations to house those displaced from their normal living circumstances. FEMA routinely provides short-term housing options in the form of portable trailers to house displaced individuals and families. When these trailers are placed in groups they are typically referred to as FEMA parks or FEMA villages. The size of the trailer parks varies considerably, with the smallest having twenty or fewer units and the larger ones holding in excess of five hundred. These accommodations are meant to be short term, and usually have an initial projected lifespan of eighteen months, after which all housing units are expected to be vacated. To expedite the process of finding alternative long-term housing, the general policy of FEMA has been to intentionally limit the services and amenities available in these trailer parks. In other words, FEMA does not want people to get too comfortable there. Instead, the goal is to encourage people to use this assistance as a temporary weigh station on the path to permanent replacement housing (see Singer 2006).

Concerns about FEMA parks themselves entered center stage in the national media after a large scale FEMA village was erected with more than 500 housing units on the outskirts of Punta Gorda Florida in the wake of Hurricane Charlie in 2004. Shortly after it was established, the local - and eventually the national - media began reporting problems with the Punta Gorda FEMA village, including drugs, property crime, rampant vandalism, prostitution, and the like (Wilkinson 2005). Some media stories reported that FEMA villages were cesspools of criminal behavior and that the law abiding residents (who comprised the large majority) were living in fear and being terrorized by vandals and criminals (Strassman 2005). Over time, those with the financial or social capital to relocate out of the FEMA village in Punta Gorda did so, leaving behind a core of the most socially marginal and dispossessed; the poorest of the poor, the disabled, the elderly, and those unwilling or unable to hold legitimate work. The process of selective outmigration from the Punta Gorda FEMA village was reminiscent of - and analogous to-William Julius Wilson's (1987) description of the formation of the black urban underclass in his famous treatise, The Truly Disadvantaged. ${ }^{1}$

\footnotetext{
${ }^{1}$ At the time of this writing (February 2007), roughly two years after Hurricane Charlie, there are still twelve trailers occupied at the Punta Gorda site, but it is scheduled to close by the end of the month (Anderson 2007).
} 
When Hurricane Katrina landed just east of New Orleans on August 29th, 2005, New Orleans experienced the now famous catastrophic flooding. In the wake of this flood the United States witnessed the largest disaster related diaspora on native soil in 100 years. Baton Rouge, which sits eighty miles northwest of New Orleans on the east bank of the Mississippi river, is the closest major city to New Orleans. It became both the organizational front line of the rescue effort and the main destination for tens of thousands of evacuees. In the days immediately following the flooding of New Orleans, Baton Rouge was literally inundated with people fleeing the New Orleans metro area and with incoming emergency personnel. The city's two universities, Louisiana State University and Southern University, both housed evacuees, as did churches, charities, and the largest entertainment venue in the city, the River Center. Baton Rouge households assumed a major role in housing the displaced. A survey conducted in the months following the diaspora revealed that 50 percent housed evacuees at some point, most of whom were family or friends (Shihadeh, Berthelot, Weil, and Lee 2006). This incredible figure illustrates well the density of social and familial networks in South Louisiana. Many evacuees decided to stay in Baton Rouge, and in short order the available rental and housing stock was completely occupied. But as is now well documented the devastation of housing in New Orleans and surrounding communities was so widespread that large numbers of the displaced had few options but to take up residence in FEMA parks.

Not surprisingly, site selection for FEMA parks took place in an intense NIMBY environment throughout the state (Aldrich and Crook 2006; Davis and Bali 2006). According to Aldrich and Cook (2006, p. 4), half of the sixty-four parishes in Louisiana immediately banned new group trailer sites. Others experienced acrimonious public meetings before siting decisions were finalized (e.g., Ascension Parish). Community public opinions were often divided and some have argued that the dark side of community social capital was revealed when the communities with a more vibrant civic culture or with more political power were more effective at retarding FEMA trailer placements than those with less social capital (Aldrich and Cook 2006; Davis and Bali 2006).

For various reasons, including the fact that it is the seat of state government and that it is a fairly spread out and accessible city, 13 FEMA village sites were established in the Baton Rouge area within nine months (Vetter 2006b). The largest, Renaissance Village, just north of the city of Baton Rouge in Baker, held at its maximum nearly six hundred housing units and 1,600 residents, and received 
tremendous media attention due to its size and the recent widely publicized problems with the Punta Gorda FEMA village. Indeed, after the Baton Rouge FEMA villages were announced and set up, the local media began reporting concern about the evacuees, how long they would stay, and what the general character of their number would be like (Bonner 2005; Vetter 2006a, 2006c).

In light of this backdrop, this analysis addresses several questions relating to negative attitudes toward the placement of FEMA parks in Baton Rouge and resident perceptions of what their own behavioral reactions would be. Drawing from the LULU and NIMBY literatures, research on the contact hypothesis, and a broad paradigm of social control, we delineate a series of hypotheses predicting who will be most likely to have negative perceptions of the FEMA parks, as well as who will be most likely to embrace one particular nonconfrontational form of social control, engaging in avoidance behaviors.

\section{BACKGROUND LITERATURE AND CONCEPTUAL FRAMEWORK}

LULUs are facilities that are often needed by communities, but that provoke some sort of negative response from some community residents. NIMBYism refers to the negative community attitudes themselves that are expressed in response to LULUs. These literatures typically focus on community attitudes regarding the siting of human service facilities like waste management operations, toxic waste dumps, low income housing, prisons, mental health facilities, and the like (see Bohon and Humphrey 2000; Dear 1992; Gibson 2005; Groothius and Miller 1994; Luloff, Albrecht, and Bourke 1998; Martin 2000; Martin and Myers 2005; Oakley 2002). Many types of facilities are essentially needed by society (e.g., garbage dumps, prisons), but are vigorously opposed by some members of the communities that might qualify for siting. The reasons for this resistance and its intensity are varied. For example, there may be negative perceptions affiliated with the siting of the facility such as more crime or declining property values, or there may just be a more generalized philosophical opposition to it (e.g., being opposed to nuclear power). Dear (1992) argues that community perceptions are not necessarily fixed with respect to LULUs, but that in fact some are more acceptable than others. Put simply, some facilities might make for better neighbors. As Martin (2000) concedes, this makes it very difficult to predict and explain variation in these attitudes; although, it has been the assumption that community reaction will 
mostly be negative when there are common negative stereotypes associated with the facility, such as might be the case with prisons or mental hospitals.

Luloff and colleagues (1998) and others have echoed this sentiment by pointing out that NIMBYism is not a theory but a concept-a principle under which to classify certain behaviors, attitudes, or social processes. ${ }^{2}$ Because of this, it is difficult to delineate hypotheses directly from the NIMBY framework. According to Dear (1992), proximity to the proposed facility site is usually the most important factor influencing NIMBY attitudes. Those who are more proximate are likely to hold more negative attitudes, while those who are farther away should be less concerned. In an important test of the proximity thesis, Martin (2000) used community survey data to examine how the siting of a prison in a community affected perceptions of crime and safety attitudes among residents. His key finding is that those living closest to the site were more negative than those who lived farther away. This study thus provides a good example of how the siting of a facility may affect community attitudes in an uneven manner. ${ }^{3}$

A related issue is that, if the proposed facility also has an identifiable population associated with it, there is substantial literature to suggest that the process of sorting out these attitudes is even more difficult. Specifically, expectations from the literature on the contact hypothesis can also be brought to bear on the issue of attitudes toward FEMA parks. The most prominent version of the contact hypothesis was put forth by Allport (1954), who argues that prejudice and distrust of targeted groups (or outgroups) stems from ignorance, misperceptions, untruths, and fears related to these. Thus, higher levels of intergroup contact should naturally dispel the misperceptions, reduce fear, increase trust, and generally enhance intergroup perceptions. In accordance with this expectation, an ongoing body of research generally finds support for the contact hypothesis (Lee, Farrell, and Link 2004; Meer and Freedman 1966; Reed 1980; Sigelman and Welch 1993), reporting that negative feelings may soften when there is contact between different groups. The implication here is also that

\footnotetext{
${ }^{2}$ It is notable that several authors call the phenomenon NIMBY syndrome (see Kraft and Clary 1991; Lake 1993; Smith and Marquez 2000).

${ }^{3}$ Luloff and colleagues (1998) argue that a major shortcoming of the NIMBY perspective is that it really is not able to explain why this is the case. That is, some people in close proximity to a nuclear reactor may be resistant because of concerns over their property value, while others in close proximity may be resistant to a nuclear reactor being sited in their or anyone else's community. Others would argue that this point is somewhat moot from a practical and planning perspective, and that in fact the distrust inherent in NIMBYism flows from both sides of the conflict (Smith and Marquez 2000).
} 
proximity to facility sites, in this case FEMA parks, can also be hypothesized to be associated with less negative perceptions, in direct contrast to the NIMBY hypothesis.

Interestingly, there is also some evidence to suggest that this is not always the case. Specifically, some have persuasively argued that the effects of contact are really conditional. For example, interracial contact may reduce prejudice and increase tolerance when the contact occurs between members of the groups that are of relatively equal status (the status equality condition-see Allport 1954). When this is not the case, though, contact itself may have no effect on perceptions or may make them even worse. This aligns very closely with Dear's (1992) argument that the NIMBY syndrome is much more pronounced when those with what he calls "social diseases," like criminals and drug users, are going to be the new neighbors (i.e., those with low status). Moreover, contact with these low status groups does not have to be directly experienced, and in fact the group members do not even have to be low status. As Lee and his colleagues (2004) argue, contact can be experienced vicariously through the media or through accounts from friends or other social network members. Moreover, the objective status of the outgroup does not even really matter because it is the subjective perceptions that are of interest. With respect to the FEMA parks, one is hard pressed to find media coverage that even resembles portraying them as high-status, safe, or desirable places. To the contrary, FEMA parks and their residents have widely been portrayed as being near the lower echelons of the social structure, which for the most part may not be too far off the mark. As Davis and Bali (2006, p. 5) note, "While we do not have survey evidence on evacuees' sociodemographics, it seems likely that FEMA's trailer parks benefit individuals in similar economic circumstances as the nation's other income maintenance programs." Bringing this logic full circle back to the status equality condition, status differences, thus, become a critical component of the equation in explaining individual variation in attitudes toward the FEMA parks. To flesh this theme out, we thus turn to the literature on social control, specifically Donald Black's (1983) work on the social structure of social control. Our main assumption here, articulated in greater detail below, is that NIMBY related attitudes and behaviors are in large part attempts at social control.

Black (1983, p. 34) defines social control as "any process by which people define or respond to deviant behavior." Because NIMBY attitudes and behaviors clearly fit the bill in terms of being a response to a perceived threat to the community, it should be possible to draw on the general theory of social control to predict who is most likely to 
apply the social control and what forms of social control may be expected. In the present case this means predicting which people are likely to hold the most negative perceptions of FEMA parks and, subsequently, which are most likely to implement avoidance behaviors. Avoidance is a subtype of a specific form of social control, inaction (see Horwitz 1990), and can also be considered a form of self-help social control (Black 1998). ${ }^{4}$ It is particularly germane to the present case because avoidance is not only the main goal of NIMBY movements that block facility placement (see Groothuis and Miller 1994), but is also relevant after a facility has already been sited. Furthermore, it is widely used not just in cases of overt conflict (e.g., when spouses are in the process of a divorce, but still reside in the same abode), but also as a way to manage anticipated conflict.

In his general theory of social control, Black (1998) relates that the nature and intensity of social control can typically be understood by considering the social structure of the event, that is, the status of the people exerting the social control and those who are being subjected to it, as well as the nature of the social ties among the people. In the present study, we are concerned at a very broad level with attitudes toward FEMA parks by an average cross-section of the general public in the community in which FEMA parks were being placed; thus we anticipate that based on the theoretical framework we will be able to discern group-based differences in attitudes toward the FEMA parks and, hence, systematic variations in attempts at social control or what we might more appropriately call in the present case "anticipated social control.",

\section{THE CONTOURS OF SOCIAL CONTROL}

Black identifies several styles of social control, which refer to "the type of responses normative violations elicit" (Horwitz 1990, pp. 16-17). Among these are the penal, compensatory, conciliatory and therapeutic styles. There are also several forms of social control. The forms that social control efforts take refer to what people actually $d o$ in response to what they perceive to be deviant. Included here are

\footnotetext{
${ }^{4}$ Other types of inaction include tolerance and exiting the situation altogether.

${ }^{5}$ It should be noted that some (Phillips 2003) have made it clear that Donald Black in his voluminous writings treats social control and the concept of "conflict management" interchangeably. Thus we issue the disclaimer that we do not take a literal translation of Blackian theory and utilize it to explain attitudes toward FEMA parks. This imputes more "conflict" that needs to be managed to the relationship between FEMA parks and the community than is probably the case. Rather, our utilization of many concepts drawn from this perspective should be construed in a manner that is more analogous than literal.
} 
inaction, unilateral and bilateral aggression, and trilateral forms. Concrete examples of each of these forms would include, respectively, avoidance, murder, two-way negotiations, and reliance on a third party to mandate a solution (e.g., binding arbitration).

In the present case we focus on avoidance. Avoidance involves intentionally staying away from or limiting interaction with a specific person, group, institution, or place. Avoidance is essentially a minimalist form of social control. It does not involve the use of sanctions, but also does not entail complete tolerance. Avoidance is a form of social control that is directly relevant to the negative perceptions entailed in NIMBY attitudes discussed above. Indeed, we would submit that perhaps the most common response to such negative perceptions is avoidance, in large part because it can easily be invoked against facilities or complete strangers with few or no detrimental social costs involved for the person doing the avoiding. It is also relevant to the FEMA parks because they are not randomly distributed in a community, but are spatially fixed, typically well identified, and, thus, can consciously be avoided.

The theory of social control relies on the concept of social space and the social statuses within that space to generate expectations regarding who is most likely to implement various social control mechanisms. In the present case, the concern is with who is most likely to hold negative perceptions and by extension who is then most likely to implement avoidance techniques. There are several general principles that guide the expectations generated below, including that (1) the degree of relational distance between parties (close or distant) shapes social control efforts; (2) the presence of hierarchical relationships (superordinate and subordinate) determines the contours of social control efforts; and (3) the extent of crosscutting ties, or common relationships, determines the types of social control used because it influences the ability to rely on third parties to intervene.

Black (1998) identifies several dimensions of social space, and where groups of people are positioned in social space along various status dimensions determines, according to the theory, the nature and intensity of the social control function. Generally speaking, we anticipate that the more distant people are from FEMA parks and their residents in social space, the more likely they are to engage in avoidance type behaviors. ${ }^{6}$ Underlying this are the assumptions that

\footnotetext{
${ }^{6}$ One helpful reviewer was interested in our distinctions between the FEMA parks versus the residents of the parks themselves. While we are ostensibly focused on attitudes toward and behaviors regarding the parks, it is difficult to fully disentangle the two. The parks themselves should not necessarily be a problem for any community, if they have zero residents.
} 
there are effectively (1) no preexisting meaningful relationships between the two groups, (2) no meaningful hierarchical relationships aside from those inherent in the dimensions of social space outlined below, and (3) basically no crosscutting ties between the two groups. With all of these factors reasonably held at zero, the main determinants of avoidance implementation should be the social structural positions of respondents.

The first dimension of social space is vertical status. Vertical status refers to objective position in the stratification system based on income or wealth. Considering first the position of the FEMA parks, because their sole intent is to provide housing for those who do not have shelter, they are almost by definition a low-status facility. Those who are lucky enough to enjoy high vertical status will either have the financial means to avoid having to relocate to a FEMA village, or will have sufficient social capital (which is also a function of vertical status) to avoid it. Either way, those who consider themselves to be of higher vertical status are hypothesized to be more likely to hold negative perceptions and to engage in avoidance behaviors. They have the resources and the inclinations to avoid, and, in the absence of any functionally dependent relationships with FEMA parks (i.e., working there as an employee), essentially have no good reason not to avoid.

A second dimension of social space is radial status, which refers to the degree of integration people experience. As Cooney (1997) notes, integration is typically indexed as employment or marital status, with those who are gainfully employed or married enjoying more radial status than those who are not. It seems reasonable that the social capital literature is also relevant here, specifically how integrated people are in their social lives. Social capital refers to the degree of interpersonal and institutional networks, norms, and trust to use Putnam's (2000) terms. Because the well-integrated are distant in social space from FEMA parks and their residents, they are anticipated to both hold more negative attitudes toward FEMA parks and to be more likely to use avoidance measures.

A third dimension of social space is cultural status or participation in the culture of the majority. In the present case we would suggest that racial identity is a particularly good indicator of cultural status, as would be educational attainment. A very large proportion of the evacuees displaced into the FEMA trailer parks around Baton Rouge were African American, and the common portrait put forth by the media was of a minority evacuee. We would expect that because of social distance between blacks and whites on this dimension, that whites will be more likely to use avoidance techniques, while African Americans will be less likely to use them. 
A fourth dimension of social space can be called normative status, or respectability. Black and others argue that a good indicator of normative status would be some sort of proxy for the degree of social control experienced. To illustrate, Cooney (1997) in his discussion of homicide argues that having an arrest record is a good indicator of being subjected to the social control efforts of others, and hence relatively low normative status. In the present case, we anticipate a good proxy for normative status would be an indicator for respondents who anticipate they would also end up in a FEMA trailer park if the same thing happened to them. Consistent with the other statuses discussed above, we anticipate that those with lower normative status will be both less likely to develop negative perceptions and less likely to engage in avoidance behaviors.

To summarize, the LULU and NIMBY literatures and the literature on the contact hypothesis lead us to anticipate that spatial proximity to FEMA parks could generate either more or less negative perceptions, depending on the accuracy of the status equality assumption. In contrast, the social control paradigm leads us to expect that those of higher social status along a variety of dimensions will have more negative perceptions of the FEMA parks and be more likely to engage in avoidance behaviors. With these expectations delineated, we turn to the empirical portion of the analysis. ${ }^{7}$

\section{DATA, MEASURES, AND RESEARCH METHODS}

\section{Data}

The data for this study were collected as part of a multiwave data collection effort in the wake of Katrina. Specifically, in the first wave which was collected from September to November of 2005, more than 1,300 telephone interviews were conducted with members of East Baton Rouge Parish households, who lived there before the storm. A second wave of data comprising interviews with 1,008 people was collected during February and March of 2006, with the timing intentionally targeted for six months after the storm. When the first wave of data collection was launched, it was not yet apparent how important the issue of FEMA housing was going to be. When it did become apparent, the survey instrument for the anticipated second wave of data collection was augmented to include a module

\footnotetext{
${ }^{7}$ The fifth dimension of social space is organizational status. It is not clear exactly how organizational status should be operationalized with individual-level attitudinal data, and so, following others, we omit it from our analysis below.
} 
directly questioning respondents about their attitudes toward the FEMA parks. It is, therefore, only the second wave of data that is utilized in the analysis below and all measures are derived from that sample.

The survey instrument included a number of questions directly referring to the FEMA trailer parks and their residents. The specific wording for these and other questionnaire items from which we develop the measures derived below are provided in Appendix A. We are specifically interested in how warm or hostile Baton Rouge residents feel toward the FEMA parks, and in their exercise or anticipated exercise of avoidance techniques. Our initial screening question asked Baton Rouge residents how close they lived to the nearest FEMA park. If they lived within a half mile of one, we phrased the questions in the form, "Since the trailer park was placed near your neighborhood, have you done any of the following because of the trailer park?" If the respondents lived more than a half a mile away, we phrased the questions as, "If a trailer park was placed near your neighborhood, would you do any of the following?" As we expected, a relatively small proportion of our respondents, about $11 \%$, actually lived within a half a mile of a FEMA park. We, therefore, retain those who live within a half a mile and those who do not in our sample, and create a dummy variable coded 1 for living within a half a mile of a trailer park and 0 otherwise. This variable essentially indexes spatial proximity, an important concept from the NIMBY literature and the contact hypothesis.

\section{Outcome Variables}

Our first set of indicators is meant to tap into attitudes reflecting negative perceptions of the FEMA parks. For this we utilize three items, listed in Appendix A. The percentage distributions for these variables are presented in Table 1 . Here respondents were asked if they thought trash and litter, crime, and local property values going down would be a problem for their neighborhood due to the trailer park being sited locally. We dichotomized the response categories for these variables with dummy variables coded 1 for yes and 0 otherwise. As the descriptive statistics indicate for these variables, between $57 \%$ and $61 \%$ of respondents hold a negative perception of the trailer parks and their residents. For the multivariate analysis which follows, we analyze each of these as a separate outcome using logistic regression, but we also transform these three variables into a single index by retaining the weighted 
Table 1. Descriptive statistics

\begin{tabular}{|c|c|c|c|}
\hline & $\% /$ Mean & & S.D. \\
\hline \multicolumn{4}{|l|}{ Outcome Variables } \\
\hline \multicolumn{4}{|l|}{ Stigma Index Components } \\
\hline Trash and litter would become a problem & & 57.9 & \\
\hline Crime would become a problem & 56.9 & & \\
\hline Property values would go down & 61.2 & & \\
\hline \multicolumn{4}{|l|}{ Avoidance Index Components } \\
\hline Change driving routes & 26.9 & & \\
\hline Move or sell & 21.3 & & \\
\hline \multicolumn{4}{|l|}{ Explanatory Variables } \\
\hline \multicolumn{4}{|l|}{ Vertical Status } \\
\hline Income & $59,325.26$ & & 33697.20 \\
\hline \multicolumn{4}{|l|}{ Radial Status } \\
\hline Marital status & 54.0 & & \\
\hline Informal socialization index items & 19.45 & & 5.00 \\
\hline Associational participation index items & 2.67 & & 1.99 \\
\hline \multicolumn{4}{|l|}{ Cultural Status } \\
\hline White & 58.0 & & \\
\hline \multicolumn{4}{|l|}{ Educational attainment } \\
\hline H.S. or less & 26.5 & & \\
\hline Some college & 21.5 & & \\
\hline College degree + & 42.0 & & \\
\hline \multicolumn{4}{|l|}{ Normative Status } \\
\hline Likely to live in FEMA park & 33.2 & & \\
\hline \multicolumn{4}{|l|}{ Contact Variables } \\
\hline Live near trailer park & 11.6 & & \\
\hline See trailer park residents & & 20.8 & \\
\hline \multicolumn{4}{|l|}{ Control Variables } \\
\hline Age & 42.4 & & 15.8 \\
\hline Male & 47.5 & & \\
\hline Social trust index & .077 & & .872 \\
\hline Interracial trust index & -.005 & & .837 \\
\hline
\end{tabular}

factor scores from a principal components analysis where all variables loaded highly on the same factor. ${ }^{8}$

Our second main indicator of interest is a measure of avoidance behaviors. To measure this construct we draw two questions from a larger battery on responses to having a FEMA park sited in one's neighborhood. The first item queries respondents on whether they will change driving routes because of the trailer park and the second asks respondents to indicate whether they would move or sell their home because of the trailer park. The response options for these variables

${ }^{8}$ Our initial extraction resulted in component loadings ranging from .734 to .841 on a single factor with an Eigenvalue of 1.876 and 62.5 percent of the variance explained. 
are the same as for the prior set. As Table 1 indicates, about one fifth to one fourth of the respondents anticipates engaging in avoidance behaviors. Like the measures of negative perceptions, we analyze the avoidance outcomes both as separate dichotomous items and as an interval level avoidance index derived from the average of the standardized scores of these two measures. Higher values on this index indicate a greater likelihood of implementing an avoidance behavior.

\section{Primary Explanatory Variables}

Aside from these measures of negative perceptions and avoidance techniques, we derive numerous indicators of our primary theoretical constructs of the various dimensions of social space. To index vertical status we utilized respondents' income, which is based on a sevencategory ordinal scale that we recoded to the midpoints in keeping with convention in the literature. Radial status, or integration is measured with a dummy variable coded 1 for married respondents and 0 for all others. A second measure of radial status is an informal socialization index developed from items replicated from Putnam's (2000) forty cities survey instrument. Specifically, we develop an index that characterizes the degree of informal socialization from items measuring whether respondents had recently had friends to their home, visited relatives, socialized with coworkers, played cards or board games with friends, or just hung out with friends. A third is an index of associational involvement, and is constructed as an additive index from a series of items tapping into participation in sports clubs; youth organizations; parents associations, like PTA; church activities; neighborhood associations; charitable organizations; professional organizations; hobby; investment or garden societies; or other clubs. These questionnaire items are reported in Appendix A.

Cultural status, or conventionality and alignment with the culture of the majority is measured as a dummy variable coded 1 for white respondents and 0 otherwise. Following Cooney (1997) we also measure cultural status as educational attainment using a collapsed three-category measure capturing less than high school, at least a high school degree, and some college experience or more. ${ }^{9}$ Finally, to round

\footnotetext{
${ }^{9}$ While we use an operationalization that is consistent with prior research, one reviewer pointed out that educational attainment could be construed as a measure of vertical status as well. We concur, and recognize both the status attainment and socialization aspects of formal education. We caution the reader on the potential dual interpretation of this variable, but also note that from our conceptual framework the directional association of this variable with the outcomes of interest should be the same.
} 
out our operationalization of the relevant dimensions of social space we measure normative status with a dummy variable coded 1 for those respondents who indicate that it is likely that they would end up as the resident of a FEMA trailer park, if the same experienced a similar disaster and 0 otherwise. Because this item measures low status on this dimension, unlike our other indicators described above, we expect it to have a negative relationship with our outcomes.

We measure spatial proximity and contact with FEMA parks with the measure of living within a half mile of a park reported above, as well as a second measure. The second measure, reported in Appendix $\mathrm{A}$, is a dummy variable coded 1 if the respondents see the residents of the trailer parks sometimes or almost every day and 0 otherwise. As Table 1 indicates, nearly 21 percent of the respondents indicate that this is the case.

\section{Controls}

In addition to all of these measures, we include several control variables. Age of the respondent is measured in years and gender is captured with a dummy variable coded 1 for males and 0 otherwise. It also seemed prudent to partition out the degree of social trust and interracial trust that respondents exhibited because trust is both an element of the social capital paradigm we mentioned above and because it seems pertinent to the propensity to adopt avoidance behaviors. To capture each of these constructs we utilized multi-item indices, the specific items for which are also contained in Appendix A. The scales we used are derived from an obliquely rotated principle components factor analysis, the results of which are reported in Appendix B. As expected, this analysis resulted in a clear interracial trust scale and a clear generalized trust scale.

\section{RESULTS}

Table 2 presents the results from our ordinary least squares (OLS) regression analysis predicting the negative labels index that captures negative perceptions of FEMA parks. The results from this model are fairly straightforward. Most of the theoretical variables do not have a statistically significant relationship with stigma-related attitudes. The one exception to this is our indicator for those likely to have to live in a FEMA trailer, which indexes low normative status. The negative coefficient for this variable is in the expected direction and, substantively, it means that those who would be more likely to have to take up residence in a FEMA trailer, if a similar natural disaster struck 
Table 2. OLS regression model predicting negative labels index

\begin{tabular}{lccc}
\hline & Coeff. & St. Error & Beta \\
\hline Vertical Status & & & \\
$\quad$ Income & .000 & .000 & .075 \\
Radial Status & & & \\
$\quad$ Marital status & .087 & .087 & .044 \\
$\quad$ Informal socialization index & $.022^{*}$ & .009 & .112 \\
$\quad$ Associational participation index & -.017 & .021 & -.034 \\
Cultural Status & & & \\
$\quad$ White & -.026 & .092 & -.013 \\
$\quad$ Educational attainment & -.030 & .055 & -.025 \\
Normative Status & & & \\
$\quad$ Likely to live in FEMA park & $-.324^{* *}$ & .089 & -.157 \\
Contact & & & \\
$\quad$ Live near trailer park & $-.354^{* *}$ & .139 & -.116 \\
See trailer park residents & $.377^{* *}$ & .104 & .157 \\
$\quad$ Age & .000 & .003 & -.005 \\
Male & -.122 & .079 & -.063 \\
Social trust index & -.079 & .053 & -.065 \\
Interracial trust index & $-.267^{* *}$ & .047 & -.229 \\
$\mathrm{R}^{2}$ & .126 & & \\
$\mathrm{~N}$ & 567 & & \\
\hline${ }^{*} \mathrm{p}<.05$. & & & \\
${ }^{* * *} \mathrm{p}<.01$. & & &
\end{tabular}

their household, are less likely to hold negative attitudes toward FEMA village residents.

The performance of a few other variables is also noteworthy. The two measures of contact, living near a FEMA park and seeing trailer park residents, are both associated with the outcome. Those who live closer to FEMA parks are less likely to hold negative perceptions, while those who see the trailer park residents fairly regularly are more likely to hold negative perceptions. This suggests that negative perceptions of the FEMA parks may be influenced by both lack of spatial proximity (which might imply a standard prejudice without contact) and conflict based on actual contact. Finally, the indicator for interracial trust reveals that those who have a high degree of interracial trust are less likely to hold negative perceptions of the FEMA parks. Overall, this model explains about 13 percent of the variance.

In Table 3 we extend this analysis and examine each of the three measures contained in the index separately using logistic regression. The rationale for this is that, if there are variations in the effects of the explanatory variables on the separate components of the index, 
Table 3. Odds ratios from logistic regression models predicting dichotomized negative labeling items

\begin{tabular}{lccc}
\hline & \multicolumn{2}{c}{ Trash and Litter crime } & Property values \\
\hline Vertical Status & & & \\
$\quad$ Income & 1.000 & 1.000 & $1.000^{*}$ \\
Radial Status & & & \\
$\quad$ Marital status & 1.094 & 1.245 & .905 \\
$\quad$ Informal socialization index & 1.028 & 1.005 & 1.029 \\
$\quad$ Associational participation index & .962 & 1.041 & .969 \\
Cultural Status & & & \\
$\quad$ White & $.659^{*}$ & $1.770^{* *}$ & 1.040 \\
$\quad$ Educational attainment & .895 & .901 & 1.018 \\
Normative Status & & & \\
$\quad$ Likely to live in FEMA park & $.514^{* *}$ & 1.010 & $.508^{* *}$ \\
Contact & & & $.303^{* *}$ \\
$\quad$ Live near trailer park & $.360^{* *}$ & $.484^{*}$ & $1.882^{*}$ \\
See trailer park residents & $1.885^{*}$ & $1.793^{*}$ & .997 \\
Age & 1.000 & 1.001 & $.604^{* *}$ \\
Male & .788 & .886 & .870 \\
Social trust index & 1.027 & $.743^{*}$ & $.762^{*}$ \\
Interracial trust index & $.738^{* *}$ & $.568^{* *}$ & .129 \\
Nagelkerke R ${ }^{2}$ & .095 & .119 & 567 \\
N & 567 & 567 & \\
\hline${ }^{*} p<.05$. & & & \\
${ }^{* *}$ p $<.01$. & & &
\end{tabular}

then leaving them combined into an index may mask important variations. The odds ratios are reported in Table 3 along with a measure of model fit and coefficient significance tests. The first logistic regression model predicts concern over trash and litter, the second concern over crime, and the third concern over declining property values. Since these are odds rations, a value of 1 means that the odds are even, a value below 1 is indicative of lower odds, and a value above 1 is indicative of higher odds. The general pattern of these models is that those with lower normative status have lower odds of being concerned about trash and litter or declining property values, and those who actually live near a trailer park feel the same way about all three of these outcomes, as do those with higher values on the interracial trust index. Those who see trailer park residents more frequently have higher odds of having negative perceptions regarding all three outcomes. Interestingly, whites have much higher odds of being concerned about crime, but lower odds of being concerned about trash and litter. 
Table 4. OLS regression model predicting avoidance

\begin{tabular}{|c|c|c|c|c|c|c|}
\hline & \multicolumn{3}{|c|}{ Model 1} & \multicolumn{3}{|c|}{ Model 2} \\
\hline & Coeff. & St. Error & Beta & Coeff. & St. Error & Beta \\
\hline Stigma Index & - & - & - & $319^{* *}$ & .035 & .361 \\
\hline \multicolumn{7}{|l|}{ Vertical Status } \\
\hline Income & .000 & .000 & .031 & .000 & .000 & .004 \\
\hline \multicolumn{7}{|l|}{ Radial Status } \\
\hline Marital status & -.075 & .077 & -.044 & -.103 & .072 & -.060 \\
\hline $\begin{array}{l}\text { Informal socialization } \\
\text { index items }\end{array}$ & .014 & .008 & .083 & .007 & .007 & .043 \\
\hline $\begin{array}{l}\text { Associational participation } \\
\text { index items }\end{array}$ & .024 & .019 & .055 & .029 & .018 & .067 \\
\hline \multicolumn{7}{|l|}{ Cultural Status } \\
\hline White & $.324^{* *}$ & .082 & .186 & $.333^{* *}$ & .076 & .191 \\
\hline Educational attainment & -.070 & .049 & -.068 & -.062 & .046 & -.059 \\
\hline \multicolumn{7}{|l|}{ Normative Status } \\
\hline Likely to live in FEMA park & $-.274^{* *}$ & .078 & -.150 & $-.171^{*}$ & .074 & -.093 \\
\hline \multicolumn{7}{|l|}{ Contact } \\
\hline Live near trailer park & -.090 & .123 & -.034 & .023 & .115 & .008 \\
\hline See trailer park residents & $.324^{* *}$ & .092 & .153 & $.203^{*}$ & .087 & .096 \\
\hline Age & .000 & .002 & .008 & .001 & .002 & .009 \\
\hline Male & -.004 & .070 & -.003 & .034 & .066 & .020 \\
\hline Social trust index & $-.146^{* *}$ & .042 & -.142 & -.039 & .043 & -.036 \\
\hline Interracial trust index & -.064 & .046 & -.060 & -.061 & .040 & -.060 \\
\hline $\mathrm{R}^{2}$ & .125 & & & .238 & & \\
\hline $\mathbf{N}$ & 567 & & & 567 & & \\
\hline
\end{tabular}

${ }^{*} \mathrm{p}<.05$.

${ }^{* *} \mathrm{p}<.01$.

In Table 4 we tackle the next portion of our analysis by examining avoidance behaviors. In this case OLS regression is used to predict variation in the avoidance index with our explanatory variables. The first model predicts this index with the baseline set of variables derived from the social control framework explicated above. The second model incorporates the negative perceptions index as a way to gauge the effects of NIMBYism on avoidance behaviors, net of the social status characteristics. Based on the integrated conceptual framework delineated above, we generally expect that the more distant respondents are in social space from FEMA parks, the more likely they are to indicate they will implement avoidance behaviors. We also expect that those with more negative perceptions of the parks, or more pronounced NIMBY attitudes, will also be more likely to avoid. The results of these models presented in Table 4 
Table 5. Odds ratios from logistic regression models predicting dichotomized avoidance indicators

\begin{tabular}{lcccr}
\hline & Change driving routes & \multicolumn{3}{c}{ Sell homes } \\
\hline $\begin{array}{l}\text { Stigma Index } \\
\text { Vertical Status }\end{array}$ & - & $2.724^{* *}$ & - & $3.395^{* *}$ \\
$\quad$ Income & 1.000 & 1.000 & 1.000 & 1.000 \\
Radial Status & & & & \\
$\quad$ Marital status & .762 & .709 & .868 & .792 \\
$\quad$ Informal socialization index items & 1.018 & 1.000 & $1.052^{*}$ & 1.036 \\
$\quad$ Associational participation index items & 1.063 & 1.080 & 1.073 & 1.100 \\
Cultural Status & & & & \\
$\quad$ White & $1.877^{*}$ & $1.925^{*}$ & $3.050^{* *}$ & $3.288^{* *}$ \\
$\quad$ Educational attainment & .795 & .811 & .888 & .943 \\
Normative Status & & & & \\
$\quad$ Likely to live in FEMA park & $.418^{* *}$ & $.468^{* *}$ & $.532^{*}$ & .684 \\
Contact & & & & \\
$\quad$ Live near trailer park & .937 & 1.622 & .610 & 1.097 \\
$\quad$ See trailer park residents & $2.748^{* *}$ & $2.212^{* *}$ & 1.638 & 1.336 \\
$\quad$ Age & 1.004 & 1.006 & .997 & .996 \\
$\quad$ Male & .906 & 1.004 & 1.112 & 1.274 \\
$\quad$ Social trust index & .811 & .855 & .889 & .979 \\
Interracial trust index & $.721^{* *}$ & .883 & $.704^{* *}$ & .884 \\
$\quad$ Nagelkerke R & .146 & .273 & .153 & .302 \\
N & 567 & & 567 & \\
\hline
\end{tabular}

${ }^{*} \mathrm{p}<.05$.

${ }^{* *} \mathrm{p}<.01$.

indicate that whites and those who see trailer park residents are more likely to avoid, while those who are more likely to end up living in a FEMA park are much less likely to avoid. Notably, the negative perceptions index entered in Model 2 has a strong positive association with avoidance behaviors. This measure accounts for about half of the effect of low normative status and about a third of the effect of seeing trailer park residents, while boosting the explained variance by about 10 percent.

Extending this analysis in Table 5 by separately examining the dichotomized components of the avoidance index reveals that the decision to change driving routes is strongly rooted in seeing the trailer park residents regularly and in the NIMBY attitudes, while the more serious decision to sell one's home is most strongly driven by the negative perceptions index and race of the respondent. Whites have much higher odds of expressing enough concern to sell their homes than members of other racial groups, net of the effects of 
the other variables in the model. Each of these equations explains nearly 30 percent of the variance according to the Nagelkerke $R^{2} .^{10}$

\section{DISCUSSION AND CONCLUSIONS}

This analysis was designed to initiate research on an apparently neglected topic in disaster related research. Specifically, for the last few years the FEMA trailer parks which provide temporary housing for those displaced by natural disasters have received terrible press. Local and national media have continually portrayed these trailer parks as deep wells of poverty, crime, and fearfulness. In light of the massive displacement of New Orleanians (what some have called Katricians) and other gulf coast residents, FEMA placed nearly fifty thousand of these trailers in Louisiana alone, and sited many right around the capital city of Baton Rouge and in nearby towns that are within East Baton Rouge parish. The largest of these, named Renaissance Village, just north of Baton Rouge in Baker, housed nearly six hundred trailer units and 1,600 souls in a desolate and isolated field with no telephone hookups.

We specifically centered our attention on the negative perceptions associated with these trailer parks, and the subsequent implementation of a specific social control mechanism-avoidance of FEMA parks by way of changing driving routes or by preparing to move or sell their home. To explain variations in this phenomenon, we drew on the NIMBY/LULU, contact, and social control literatures. The basic hypotheses that we delineated suggested that, while proximity to the parks might lead to perceptions that were more or less negative, those enjoying higher social status would generally hold more negative perceptions and be more likely to use avoidance behaviors. The main results from our analysis are that whites seem to be particularly concerned about crime associated with the FEMA parks, and that those who are more likely to end up in a FEMA park, if they experienced a disaster, have less negative attitudes and are less likely to use avoidance behaviors. Moreover, living near a trailer park was associated with less hostility, while seeing the residents more frequently was associated with more

\footnotetext{
${ }^{10} \mathrm{We}$ also examined all of these models with the separate component items from the negative perceptions index entered into the models from Tables 4 and 5 one at a time. In this case, each of these variables was strongly and statistically significantly related to the avoidance index and to changing driving routes or selling homes. We do not report the results of these models in tabular form because they provide no new information beyond what is already captured in the tables.
} 
negative perceptions. Likewise, the negative perceptions themselves largely drive avoidance behaviors.

The main question this analysis boils down to concerns the policies that govern where FEMA parks are sited. Generally speaking, if officials wish to minimize conflict over the placement of FEMA parks, then they would do well to consider the potentially countervailing influences that contact with the residents of such facilities might bring. While aside from normative status the results of our models did not provide particularly strong support for the social status and social control portion of our argument, it might be noted that this survey was conducted in a parish where 13 FEMA parks had already been sited. If anyone had been able to anticipate the fallout from Hurricane Katrina, it may have been possible to gauge community opinions about the FEMA parks beforehand. The fact that they were already in place at the time of this survey may mean that our data catch a cross-sectional snapshot of community attitudes that have already softened some. The implication here is that this may account for the failure to confirm some of our hypotheses.

It is notable that some communities in Louisiana after the hurricanes were actively lobbying to have such parks sited in their parish. Their logic was that the influx of people and services might serve as an economic development tool if handled properly. These were generally socioeconomically distressed communities anyway, desperate to shore up declining population bases and to save what was left of their public service sector jobs. While it is unlikely that FEMA parks would work well as economic development tools, if some communities are actually interested in lobbying for their placement, then this is one way to avoid potential siting controversies in other communities.

An additional question that is relevant to future research on this topic has to do with the scale of these FEMA parks. While most of them are not particularly large, the few extremely large ones are the same ones that have received a lot of media attention and negative press. While it is clearly the goal of FEMA to increase efficiency by housing large numbers of evacuees in the same temporary housing development, questions have been raised about whether this is a particularly wise move. It seems reasonable that much public consternation could be avoided, if a cap on park size were implemented, as the level of anonymity and uncertainty almost certainly goes up with the size of the settlement. In the case of Baton Rouge, the fact that with two or three exceptions most of the FEMA parks were of very moderate- to small-scale may be another factor that accounts for our failure to find strong relationships among many of our variables. That is, the public reactions that we have captured may not be as 
strong as they would be if all of the FEMA parks in the parish were as big as Renaissance Village.

In the end, while there has been some negative publicity in the year since these parks have been sited in Baton Rouge, the evidence does not indicate that their presence has caused an undue burden on public services like the police and emergency personnel, or that their presence has had particularly deleterious consequences for the communities in which they are situated. Future research might also therefore consider taking a different approach to the study of the dynamics of the FEMA parks and their host communities. Specifically, the social constructionist tradition in sociology focuses on the dynamics that lead to the social construction of public issues as social problems. It is very likely that the FEMA parks themselves, due to the proverbial "few bad apples," have received a much worse reputation than they deserve. Analyses such as ours may help to sort out the attitudinal and behavioral components of this issue, but social scientists and the general public may also benefit from the insights the social constructionist tradition might reveal, possibly explaining the discrepancy observed in Baton Rouge between concerns over these parks and the apparent lack of harm they are causing their host communities.

\section{REFERENCES}

Aldrich, Daniel P. and Kevin Crook. 2006. Strong Civil Society as a Double Edge Sword: Siting Trailers on Post-Katrina New Orleans. Working Paper \#06-11. Cambridge, MA: Weatherhead Center for International Affairs, Harvard University.

Allport, G. W. 1954. The Nature of Prejudice. Cambridge, MA: Addison-Wesley.

Anderson, Zac. 2007. "State Hopes to Avoid FEMA City Mistakes." Herald-Tribune February 18:1A.

Black, Donald. 1983. "Crime as Social Control." American Sociological Review 48:34-45.

\section{Press.}

Bohon, Stephanie A. and Craig R. Humphrey. 2000. "Courting LULUs: Characteristics of Suitor and Objector Communities." Rural Sociology 65:376-395.

Bonner, Mark F. 2005. "Alternative Sought for Trailer Park Name; Sheriff's Office Wants List of Evacuees at Baker Site." The Advocate October 28:2.

Cooney, Mark. 1997. "The Decline of Elite Homicide.” Criminology 35:381-407.

Davis, Belinda Creel and Valentina Bali. 2006. Not In My District: The Placement of FEMA Trailer Parks. Paper prepared for the Sixth Annual State Politics and Policy Conference, Texas Tech University, Lubbock, TX. 
Dear, Michael. 1992. "Understanding and Overcoming the NIMBY Syndrome." Journal of the American Planning Association 58:288-300.

Gibson, Timothy A. 2005. "NIMBY and the Civic Good." City and Community 4:381-401.

Groothius, Peter A. and Gail Miller. 1994. "Locating Hazardous Waste Facilities: The Influence of NIMBY Beliefs.” American Journal of Economics and Sociology 53:335-346.

Horwitz, Allan V. 1990. The Logic of Social Control. New York: Plenum Press.

Kraft, M. E. and B. B. Clary. 1991. "Citizen Participation and the NIMBY Syndrome: Public Response to Radioactive Waste Disposal." Western Politics Quarterly 44:299-328.

Lake, Robert W. 1993. "Rethinking NIMBY." Journal of the American Planning Association 59:87-92.

Lee, Barrett A., Chad R. Farrell, and Bruce G. Link. 2004. "Revisiting the Contact Hypothesis: The Case of Public Exposure to Homelessness.” American Sociological Review 69:40-63.

Luloff, A. E., Stan Albrecht, and Lisa Bourke. 1998. "NIMBY and the Hazardous and Toxic Waste Siting Dilemma: The Need for Concept Clarification." Society and Natural Resources 11:81-89.

Martin, Randy. 2000. “Community Perceptions About Prison Construction: Why Not In My Backyard?" The Prison Journal 80:25-294.

Martin, Randy and David L. Myers. 2005. "Public Response to Prison Siting: Perceptions of Impact on Crime and Safety." Criminal Justice and Behavior 32:143-171.

Meer, Bernard and Edward Freedman. 1966. "The Impact of Negro Neighbors on White Homeowners." Social Forces 45:11-19.

Oakley, Deidre. 2002. "Housing Homeless People: Local Mobilization of Federal Resources to Fight NIMBYism." Journal of Urban Affairs 24:97-116.

Phillips, Scott. 2003. "The Social Structure of Vengeance: A Test of Black's Model." Criminology 41:673-708.

Putnam, Robert. 2000. Bowling Alone: The Collapse and Revival of American Community. New York: Simon and Schuster.

Reed, John Shelton. 1980. "Getting To Know You: The Contact Hypothesis Applied to the Sectional Beliefs and Attitudes of White Southerners." Social Forces 59:123-135.

Shihadeh, Edward, Emily Berthelot, Matthew Lee, and Frederick Weil. 2006. "Baton Rouge Welcomes Katrina Evacuees." Fact Sheet \# 3, Crime and Policy Evaluation Research group. Retrieved September 1, 2006 from http:// www.lsu.edu/capergroup/resources/factsht.htm.

Sigelman, Lee and Susan Welch. 1993. "The Contact Hypothesis Revisited: Black-White Interaction and Positive Racial Attitudes." Social Forces 71:781-795.

Singer, Paul. 2006. "Camp FEMA." National Journal 38:20-26.

Smith, Eric R. A. N. and Marisel Marquez. 2000. "The Other Side of the NIMBY Syndrome." Society and Natural Resources 13:273-280.

Strassman, Mark. 2005. "FEMA Trailer Parks for Victims of Hurricanes." CBS Evening News October 4. 
Vetter, Kimberly. 2006a. "Deputies Gather Data at Park: Most Cooperative; Sex Offender Arrested." The Advocate February 8:B1.

- 2006b. "Living in Fear: Some FEMA Residents Say Crime Rampant." The Advocate July 2:A1.

- 2006c. "Three Arrested in Evacuee Park Check: Sheriff's Office Visited Baker Site." The Advocate February 9:B1.

Wilkinson, Peter. 2005. "Welcome to Nowhere." Rolling Stone 987:58-64.

Wilson, William J. 1987. The Truly Disadvantaged: The Inner-City, the Underclass, and Public Policy. Chicago: University of Chicago Press.

\section{APPENDIX A}

\section{Survey Items for Selected Measures Used in the Analysis}

\section{Trailer Park Proximity}

Now I'd like to ask you some questions about the trailer parks that have been set up for Hurricane evacuees.

How close do you live to the nearest trailer park? Please stop me when I get to the best answer:

\section{Next door}

Within a few blocks

Within about a half mile

Within about a mile

More than a mile

Don't know

No answer

\section{Reactions to Trailer Park}

[If within a half mile] Since the trailer park was placed near your neighborhood, have you done any of the following because of the trailer park?

[If further than a half mile, or $\mathrm{dk} / \mathrm{na}$ ] If a trailer park was placed near your neighborhood, would you do any of the following because of the trailer park?

Change driving routes

Move or sell

Yes

Would think about doing it

No

Don't know

No answer 
3. Perceptions of Trailer Parks

[If within a half mile] Since the trailer park was placed near your neighborhood, do you think any of the following has become a problem for your neighborhood?

[If further than a half mile, or $\mathrm{dk} / \mathrm{na}$ ] If a trailer park was placed near your neighborhood, do you think any of the following would be a problem for your neighborhood?

Trash and litter

Crime

Property values down

Yes

Yes, just a little

No

Don't know

No answer

4. Expectation of Living in a Trailer

If we had a disaster like Hurricane Katrina in Baton Rouge and your home was destroyed, do you think you might end up living in a place like the trailer parks?

Yes

No

Don't know

No answer

5. See People from the Trailer Park

Do you see people from the trailer parks in your neighborhood, say on the street or in stores? About how often?

Yes, almost every day or more

Yes, sometimes

Yes, but not often

No, not as far as I know

Don't know

No answer

6. Informal Socialization Scale

About how often have you... [Insert Activity]? [If Necessary Probe with Categories]

Had friends to home

Visited relatives 
Socialized with coworkers

Played cards or board games

Hung out with friends

Every week (or more often)

Almost every week

Once or twice a month

A few times per year

Less often than that

Never

Don't know

Refused

\section{Associational Participation Scale}

Now I'd like to ask whether you have taken part in activities with different groups and organizations. I'm going to read a list; just answer YES if you have been involved in the past twelve months with this kind of group.

Sports club

Youth organization

Parents' association like PTA

Activities at church

Neighborhood association

Charity organization

Professional association

Hobby, investment, or garden societies

Other clubs or organizations

\section{Interracial and Generalized Trust Scales}

Next, we'd like to know how much you trust different groups of people. First, think about (GROUP). Generally speaking, would you say that you can trust them a lot, some, only a little, or not at all?

People in your neighborhood

People you work with

People at your church or place of worship

People who work in the stores where you shop

The police in your local community

White people

African Americans or Blacks

Asian people

Hispanics or Latinos 
Appendix B. Obliquely rotated principle components factor pattern matrices for interracial trust and generalized social trust scales

Component 1

interracial trust
Component 2 generalized social trust

$\begin{array}{ll}\text { African Americans or Blacks } & .948 \\ \text { Hispanics or Latinos } & .925 \\ \text { Asian people } & .888 \\ \text { White people } & .688\end{array}$

People you work with

People in your neighborhood

People at your church

or place of worship

The police in your local community $\quad .610$

People who work in the

stores where you shop

Eigenvalue

Variance Explained 